RMD

Open

Rheumatic \&

Musculoskeletal Diseases

\title{
Orthopaedic interventions in patients with psoriatic arthritis: a descriptive report from the SPAR cohort
}

\author{
Naba Haque, ${ }^{1}$ Rik J Lories, ${ }^{1,2}$ Kurt de Vlam ${ }^{1,2}$
}

To cite: Haque N, Lories RJ, de Vlam K. Orthopaedic interventions in patients with psoriatic arthritis: a descriptive report from the SPAR cohort. RMD Open 2016;2:e000293.

doi:10.1136/rmdopen-2016000293

- Prepublication history for this paper is available online To view these files please visit the journal online (http://dx.doi.org/10.1136/ rmdopen-2016-000293).

Received 8 April 2016 Accepted 25 July 2016

\section{CrossMark}

${ }^{1}$ Department of Development and Regeneration, Skeletal Biology and Engineering Research Center, Leuven, Belgium

2Division of Rheumatology, University Hospitals Leuven, Leuven, Belgium

Correspondence to Dr Kurt de Vlam;

Kurt.devlam@uz.kuleuven.be

\section{ABSTRACT}

Objectives: To evaluate the current needs for joint surgery in patients with psoriatic arthritis (PsA).

Methods: The patient database at the Rheumatology Department of the University Hospitals Leuven, was cross-sectionally analysed using demographic, medical, laboratory, radiological and surgical data of 269 patients with PsA. Patients were grouped by the presence or absence of orthopaedic surgery and compared for gender, age, mean health assessment questionnaire (HAQ) score, current medication and disease duration. The data were assessed using descriptive statistics and Student's t-tests.

Results: Overall $48.33 \%$ of the patients underwent 1 or more orthopaedic surgeries at some point of time. A total of 280 surgical interventions were flagged in the database, including both joint sacrificing and nonjoint sacrificing procedures. Mean disease duration $\pm S D$ at the time of surgery was 1.58 years \pm 12.05 . Age of the patients with surgeries was 54.13 years \pm 11.03 SD and not different from those without surgeries ( 53.73 years $\pm 12.81 \mathrm{SD} ; \mathrm{p}=0.78$ ). $41.54 \%$ of the patients underwent a single surgery while $58.46 \%$ had multiple surgeries. A significant difference in the mean $\mathrm{HAQ}$ score was observed among the patients with and without surgeries $(p<0.001)$. Of all the surgeries $63.92 \%$ were performed after diagnosis whereas $36.07 \%$ were performed before a diagnosis of PsA was made. Among the surgeries performed before diagnosis $40.59 \%$ were arthroscopies including $9.90 \%$ of diagnostic arthroscopies.

Conclusions: The number of surgical interventions has significantly increased in patients with PsA compared with historical cohorts even with a relatively shorter disease duration. There was a significant difference in $\mathrm{HAQ}$ score between the patients with or without surgeries.

\section{INTRODUCTION}

Psoriatic arthritis (PsA) is a chronic inflammatory joint disease associated with psoriasis. ${ }^{1} 2$ The estimated prevalence of PsA around the globe varies from $0.02 \%$ to $1 \%$ whereas its prevalence in patients with

\begin{abstract}
Key messages
What is already known about this subject?

- Psoriatic arthritis (PsA) is a chronic inflammatory joint disease. Many patients with PsA develop destructive arthritis with bone erosions and loss of joint architecture often leading to loss of joint function.

What does this study add?

- The study shows an increase in the number of surgical interventions in patients with PsA irrespective of the disease duration.

- Higher HAQ score in patients who underwent surgeries reflects that the impact of disease on patients who require surgery is higher.

How might this impact on clinical practice?

- The study shows a high prevalence of joint surgery in this cohort. Early diagnosis and aggressive management of PSA from the very beginning to slow down the disease progression may reduce the risk of surgical interventions and provide an opportunity to improve the quality of life in these patients.
\end{abstract}

psoriasis ranges between $6 \%$ and $48 \% .{ }^{1} 34$ Structural damage revealed by X-rays observed in the joints of the patients with PsA appears of a similar magnitude and impact as seen in the patients with rheumatoid arthritis (RA). ${ }^{5}$ Structural damage in PsA is not limited to cartilage loss and bone erosions as in RA, but some patients with PsA also show specific features of joint remodelling with new bone formation potentially leading to joint ankylosis. Severe osteolysis clinically presenting as arthritis mutilans is also a specific feature of this disease.$^{5-9}$ PsA was for long considered a relatively benign disorder, but it has become clear that 40 $60 \%$ of all the patients will develop erosive arthritis, loss of joint architecture and associated loss of function clearly positioning PsA as a major health concern. ${ }^{141011}$ 
Current treatment strategies, and in particular specific targeting of tumour necrosis factor (TNF), are relatively effective in controlling inflammation and also significantly inhibit radiographic progression of disease, improve joint function and disease outcome by preventing joint erosions and destruction. ${ }^{12-15}$ However, in advanced cases, damage is only rarely undone and patients may require surgery to maintain or restore joint function at some point in their disease course. ${ }^{4}$ Limited literature on surgical needs and management of patients with PsA is available, and little is known about the associated outcomes. In addition, most studies have been reported before the widespread use of anti-TNF strategies.

Zangger et al reported earlier on surgery in a cohort study of 444 patients with PsA suggesting that the probability of having an orthopaedic intervention increased with the disease duration. The patients in this study had their first surgery at an average disease duration of 13.9 years, and no differences were found in the baseline characteristics and functional outcome parameters between the surgical and the non-surgical group. Out of all the patients with PsA reviewed in this cohort, only $7 \%$ of the patients required surgical management to restore function with hip arthroplasty being the most common procedure performed followed by the knee and hand surgery. ${ }^{16}$ Few years later, Zangger et $a l^{17}$ as well as Michet $e a^{18}$ showed that among all the patients with PsA undergoing surgery, a polyarticular clinical disease pattern seems to predominate, with hip and knee interventions again being the most common surgical procedures performed. The study of Michet $e t a l^{18}$ also showed that out of 504 patients with PsA, 32 $(6.30 \%)$ required hip arthroplasty in the early years of the disease in contrast to the observations of Zangger et al. Belsky and colleagues reported that out of 105 patients with PsA included in their study, 25 (24\%) underwent hand surgeries due to severe deformities. Of interest is the incidence of postsurgery infections in this cohort, which appeared high and minimal postsurgical improvement was noted. ${ }^{19}$

As most of the available data on orthopaedic surgery in patients with PsA are more than a decade old and therefore deal with patients with PsA for whom only limited medical treatment options were available, we performed a new cross-sectional analysis of orthopaedic interventions in our PsA patient cohort, thereby including a large population of anti-TNF treated patients.

\section{METHODS}

\section{Study population}

A cross-sectional analysis was carried out using the SPAR (Spondyloarthritis Registry) database at the Rheumatology Department of the University Hospitals Leuven, which contains the prospective demographic, medical, laboratory, radiological and surgical data of 269 patients with PsA in clinical follow-up from year 2000 to
2014. Patients were classified as having PsA based on the clinical assessment and ClASsification criteria for Psoriatic ARthritis (CASPAR) criteria. ${ }^{20}$ The SPAR database includes patients with all forms of disease type, severity, duration, treatment and activity, thereby representing a full spectrum of PsA as seen in a referral centre with a secondary regional and tertiary academic function. All the patients with PsA who were registered in the database and able and willing to give informed consent were included in this study. Ethical approval for the data collection was obtained from the Ethical Committee for Clinical Research at the University Hospitals Leuven.

\section{Surgical data}

The surgical data registered in the database were used for this analysis. Surgical data were recorded prospectively, and surgeries performed before diagnosis and entry into the database were retrospectively registered based on the patient's clinical history and medical records. All the musculoskeletal surgeries registered in the database were included in the analysis. One hundred and thirty patients out of 269 patients with PsA registered in the database had one or more orthopaedic surgeries related to PsA. Surgeries include both joint sacrificing (ankle prosthesis, arthrodesis, hip prosthesis, knee prosthesis, shoulder prosthesis and spine prosthesis) and non-joint sacrificing procedures (arthroscopic synovectomy, carpal tunnel syndrome (CTS), diagnostic arthroscopy, discectomy, meniscus surgery and others). The subcategory others include surgeries of feet, hand, spine, knee, wrist, shoulder, elbow, cheek, etc. As it is an exploratory study, hence all the registered musculoskeletal surgeries were included in the study. The date and year of the surgical interventions were also recorded in the database.

\section{Statistical analysis}

Basic demographic data were analysed after the database lock in December 2014. Patients were grouped depending on whether they had surgery or not. Each group was further analysed and compared on the basis of age, gender, current medication, mean HAQ score and mean disease duration at surgery. The HAQ scores recorded on the last visit for all the patients before the data analysis were used for the comparison. The data on the orthopaedic surgeries were also grouped based on whether the surgery was performed before or after the diagnosis of PsA and before or after the inclusion in the SPAR database. Data are presented as means+SD unless indicated otherwise. Groups were compared with $\chi^{2}$ test or Student's t-test/Mann-Whitney U test where appropriate. A significance level of 0.05 was used. Statistical analysis was performed using SPSS V.22.

\section{RESULTS}

A total of 269 patients with PsA were registered in the database at the time of the database lock. The general 
Table 1 Characteristics of PsA patient population

\begin{tabular}{ll}
\hline Total patients with PsA & 269 \\
Age $($ mean \pm SD) & $53.94 \pm 11.93$ \\
Male/female & $164(60.96 \%) / 104$ \\
& $(38.66 \%)$ \\
Disease duration (mean \pm SD) & $7.12 \pm 7.65$ \\
Positive family history of & $133(49.44 \%)$ \\
psoriasis & \\
Positive family history of PsA & $31(11.52 \%)$ \\
ESR (mean \pm SD) & $20.83 \pm 20.54$ \\
CRP (mean \pm SD) & $15.04 \pm 23.19$ \\
Skin involvement & $169(62.82 \%)$ \\
Nail involvement & $5(1.86 \%)$ \\
Dactylitis & $19(7.06 \%)$ \\
Enthesitis & $17(6.31 \%)$ \\
PASI score (mean $\pm S D)$ & $1.77 \pm 5.05$ \\
\hline
\end{tabular}

CRP, C reactive protein; ESR, erythrocyte sedimentation rate;

PASI, Psoriasis Area Severity Index; PSA, psoriatic arthritis.

characteristics of the PsA population are shown in table 1 . Of the 269 patients, $60.96 \%$ were males and $38.66 \%$ were females with a mean age of 53.94 years. Almost $49 \%$ of the patients had a positive family history of psoriasis, whereas $62.82 \%$ of these patients also had skin involvement with a mean Psoriasis Area Severity Index (PASI) score \pm SD of $1.77 \pm 5.05$.

One hundred and thirty (48.33\%) of the patients had one or more orthopaedic surgical interventions at some point of time. A total number of 280 surgical interventions were flagged in the database.

Baseline characteristics of both the groups (surgical vs non-surgical) in the database were compared. The patients who underwent surgeries had a mean age of $54.13 \pm 11.03$ years (range $=21-80$ years) which was not statistically different from the non-surgical group (53.73 \pm 12.81 years (range $=21-81$ years); $p=0.78$ ). The gender distribution was also not different between the surgical and non-surgical groups (male $/$ female $=64.62 \% / 35.38 \%$ and $57.55 \% / 41.73 \%$, respectively; $\mathrm{p}=0.26$; table 2 ). Of note $54(41.54 \%)$ patients who underwent surgery had a single orthopaedic intervention while 76 (58.46\%) patients underwent multiple surgeries.
Effectively, of all the 280 surgeries, 193 (68.93\%) took place before the patients were included in the SPAR database at the University Hospitals Leuven and 60 $(21.42 \%)$ were performed after their inclusion in the database. For the remaining $27(9.64 \%)$, complete data with exact dates of surgeries were not available in the database. Interestingly, 179 (63.92\%) of all these surgeries were performed after the diagnosis, whereas 101 (36.07\%) were performed before these patients were diagnosed with PsA (table 2). Among the surgeries performed before diagnosis, $40.59 \%$ were arthroscopies including $9.90 \%$ diagnostic arthroscopies.

Among the patients with PsA with surgeries, 49.23\% and $42.30 \%$ patients were treated with either anti-TNF $\alpha$ medications \pm disease-modifying antirheumatic drugs (DMARDs) or DMARDs only, respectively, whereas in the non-surgical group, $39.56 \%$ and $47.48 \%$ patients on anti-TNF $\alpha$ therapy \pm DMARDs and DMARDs only were identified ( $\mathrm{p}=0.11 ; \mathrm{p}=0.39$; table 2 ). We did not find any significant difference between the two groups based on their treatment.

A significant difference in the mean HAQ 3 score (representing the functional outcome) was observed among the patients who underwent surgeries $(0.95 \pm 0.82)$ and those who did not undergo surgeries $(0.59 \pm 0.68)$ with $p$ value of $<0.001$. For the patients who underwent surgery, the mean disease duration $\pm \mathrm{SD}$ was 1.58 years \pm 12.05 at the time of surgery with a range of -35 to 31 . We did not find any statistically significant difference in the mean age, mean disease duration and mean $\mathrm{HAQ}$ score between the patients who underwent single surgery and those who had multiple surgeries $(\mathrm{p}>0.05)$.

The details about the phenotype of PsA among the two groups are shown in table 3 . A significant difference was observed between the surgical and non-surgical group of patients with asymmetric oligoarticular PsA and peripheral and axial form of PsA, with clearly more of these patients in the surgical group, whereas least surgical interventions were observed in the patients with unspecified form of PsA. We did not find any significant difference among the rest of the PsA phenotypes (table 3).

The type of surgeries included both joint sacrificing and non-joint sacrificing procedures with more of

\begin{tabular}{lllc}
\multicolumn{2}{l}{ Table 2 Demographic data of the patients with PsA } & & \\
\hline & PsA with surgeries & PsA without surgeries & p Value \\
\hline Number of patients & $130(48.33 \%)$ & $139(51.67 \%)$ & - \\
Males/females & $84(64.62 \%) / 46(35.38 \%)$ & $80(57.55 \%) / 58(41.73 \%)$ & 0.26 \\
Mean age (years) \pm SD & $54.13 \pm 11.03$ & $53.73 \pm 12.81$ & 0.78 \\
Mean HAQ 3 score \pm SD & $0.95 \pm 0.82$ & $0.59 \pm 0.68$ & $<0.001$ \\
Number of patients currently on & & & \\
TNF- $\alpha$ blockers \pm DMARDs & $64(49.23 \%)$ & $55(39.56 \%)$ & 0.11 \\
DMARDs & $55(42.30 \%)$ & $66(47.48 \%)$ & 0.39 \\
None & $11(8.46 \%)$ & $18(12.94 \%)$ & 0.24 \\
\hline
\end{tabular}

†Mann-Whitney U test.

DMARDs, disease-modifying antirheumatic drugs; PsA, psoriatic arthritis; TNF, tumour necrosis factor. 
Table 3 Types of PsA

\begin{tabular}{lllr}
\hline Type of PsA & PsA with surgeries & PsA without surgeries & n (\%) \\
\hline Symmetric polyarthritis & $32(24.61 \%)$ & $44(31.65 \%)$ & p Value \\
Asymmetric mono/oligoarticular arthritis & $46(35.38 \%)$ & $32(23.02 \%)$ & 0.20 \\
Peripheral and axial & $20(15.38 \%)$ & $4(2.88 \%)$ & ${ }^{*} 0.02$ \\
Arthritis mutilans & $2(1.54 \%)$ & $2(1.44 \%)$ & ${ }^{*}<0.001$ \\
Predominant spondylitis & $8(6.15 \%)$ & $9(6.47 \%)$ & 0.94 \\
Unspecified & $22(16.92 \%)$ & $48(35.53 \%)$ & 0.91 \\
Total patients with PsA & 130 & 139 & ${ }^{*} 0.001$ \\
\hline${ }^{*}$ Indicates a statistically significant p value. & & & \\
PsA, psoriatic arthritis. & & & \\
\hline
\end{tabular}

Table 4 Number of individual surgeries and mean disease duration at which the surgery was performed

\begin{tabular}{|c|c|c|}
\hline Type of surgery & $\begin{array}{l}\text { Number of } \\
\text { patients } \\
\text { with PsA } \\
n(\%)\end{array}$ & $\begin{array}{l}\text { Mean } \\
\text { disease } \\
\text { duration at } \\
\text { the time of } \\
\text { surgery } \\
\text { (years) }\end{array}$ \\
\hline \multicolumn{3}{|l|}{ Joint sacrificing surgeries } \\
\hline Ankle prosthesis & $2(0.71 \%)$ & - \\
\hline Arthrodesis & $14(5.00 \%)$ & 4.53 \\
\hline Hip prosthesis & $19(6.79 \%)$ & 5.53 \\
\hline Knee prosthesis & $16(5.71 \%)$ & 7.73 \\
\hline Shoulder prosthesis & $2(0.71 \%)$ & 7.66 \\
\hline Spine prosthesis/disc & $1(0.36 \%)$ & - \\
\hline \multicolumn{3}{|l|}{ Non-joint sacrificing surgeries } \\
\hline Arthroscopic synovectomy & $22(7.86 \%)$ & 6.68 \\
\hline CTS & $19(6.79 \%)$ & -1.61 \\
\hline Diagnostic arthroscopy & $65(23.21 \%)$ & 3.45 \\
\hline Discectomy & $13(4.64 \%)$ & -3.41 \\
\hline $\begin{array}{l}\text { Meniscus operation/ } \\
\text { arthroscopy }\end{array}$ & $43(15.36 \%)$ & -7.5 \\
\hline Others & $64(22.86 \%)$ & 2.49 \\
\hline Total number of surgeries & 280 & \\
\hline
\end{tabular}

the joint sacrificing surgeries being performed in the lower limbs as compared with the upper limbs (table 4). For the joint sacrificing surgeries, the recorded mean age \pm SD of the patients at the time of surgery was 51.35 years \pm 11.83 (range $30-75$ years) Also the distribution of these surgeries among the different phenotypes of PsA is shown in table 5 with the largest number of surgeries being performed in patients with asymmetric monoarticular/oligoarticular arthritis including arthroscopies, hip and knee surgeries, surgeries for CTS and others. The subcategory of "others" in the non joint sacrificing surgeries includes $62.50 \%$ of hand and foot surgeries and $37.50 \%$ of other surgeries.

\section{DISCUSSION}

This is the first cross-sectional study on orthopaedic surgeries in patients with PsA conducted in the Belgian population and also addresses this question in the biologics era. In our study, the patients represent a full spectrum of PsA with all types, disease durations, severity, treatments and age groups. To minimise the risk of selection bias, all the patients with PsA who reported to the Rheumatology Department of the University Hospitals Leuven and gave informed consent were included in the database. All the patients underwent standard assessment and treatment at the hospital in a dedicated PsA clinic managed by trained and experienced rheumatologists with specific interest in the disease. There is a risk for multiple testing. However, this was an explorative study and no correction for multiple testing was therefore used. The results showed that $48.33 \%$ of the patients with PsA required one or the other surgical intervention at some point in time out of which two-third of the surgeries were performed after they had been diagnosed with PsA. This number is much greater than the numbers reported by Zangger et al who showed that only $7 \%$ of patients with PsA required surgery once the diagnosis of PsA had been established. In our cohort, we also found a much shorter mean disease duration of $1.58 \pm 12.05$ years at the time of surgery with a range of -35 to 31 years as compared with the mean disease duration of 13 years (range $=1-46$ years) in an earlier report. ${ }^{16}$ Similarly as compared with a study on patients with RA the, number of surgical interventions increased in patients with PsA even with a lower mean disease duration and age as compared with the patients in the RA group who had a mean disease duration of $8 \pm 6.9$ years and mean age of $57 \pm 12$ years. ${ }^{21}$ Several factors could play a role in these remarkable differences: (1) PsA is currently much more actively managed and referral to surgery may therefore occur quicker than before; (2) the road towards diagnosis and treatment may show geographical and historical differences with referral patterns for instance in case of monoarthritis being different between countries and regions; and (3) local settings may or may not facilitate the interactions with orthopaedic surgeons. Our surgery prevalence numbers could be influenced by the fact that this study was performed in a centre with a secondary regional and tertiary academic function. 
Table 5 Distribution of different types of surgeries among the various phenotypes of PsA

\begin{tabular}{|c|c|c|c|c|c|c|}
\hline Types of surgery & $\begin{array}{l}\text { Peripheral } \\
\text { and axial } \\
\text { n=20 }\end{array}$ & $\begin{array}{l}\text { Symmetric } \\
\text { polyarthritis } \\
\mathrm{n}=32\end{array}$ & $\begin{array}{l}\text { Asymmetric } \\
\text { oligoarticular } \\
\text { arthritis } \\
\mathrm{n}=46\end{array}$ & $\begin{array}{l}\text { Arthritis } \\
\text { mutilans } \\
\mathrm{n}=2\end{array}$ & $\begin{array}{l}\text { Predominant } \\
\text { spondylitis } \\
n=8\end{array}$ & $\begin{array}{l}\text { Unspecified } \\
n=22\end{array}$ \\
\hline Meniscus operation/arthroscopy & 14 & 10 & 17 & 0 & 0 & 2 \\
\hline Diagnostic arthroscopy & 8 & 19 & 28 & 0 & 4 & 6 \\
\hline Others & 12 & 19 & 17 & 2 & 3 & 11 \\
\hline Hip prosthesis & 4 & 6 & 3 & 0 & 6 & 0 \\
\hline Discectomy & 2 & 7 & 4 & 0 & 0 & 0 \\
\hline Arthroscopic synovectomy & 2 & 5 & 9 & 0 & 0 & 6 \\
\hline Knee prosthesis & 2 & 4 & 6 & 0 & 1 & 3 \\
\hline Arthrodese & 4 & 5 & 4 & 0 & 1 & 0 \\
\hline Shoulder prosthesis & 0 & 1 & 1 & 0 & 0 & 0 \\
\hline CTS & 0 & 4 & 10 & 0 & 1 & 4 \\
\hline Spine prosthesis disc & 0 & 1 & 0 & 0 & 0 & 0 \\
\hline Ankle prosthesis & 0 & 0 & 1 & 0 & 1 & 0 \\
\hline Total number of surgeries & 48 & 81 & 100 & 2 & 17 & 32 \\
\hline
\end{tabular}

Our study results also showed a significant $(p<0.001)$ difference in the mean HAQ 3 score among the patients who underwent orthopaedic surgical interventions and those who did not, unlike Zangger et $a l^{16}$ who did not find any significant difference among the two groups. This appears to suggest that the impact of disease on patients who require surgery is higher. We did not have complete HAQ score data before and after the surgeries as a large number of surgeries were performed before inclusion in the SPAR database. We therefore used the HAQ score for all the patients recorded on the last visit to compare the current status and long-term impact of surgical interventions on patient's quality of life.

As shown in the previous studies in the literature, our data also suggest that among all the joint sacrificing surgeries performed on the patients with PsA, hip and knee surgeries were the most common procedures required in the management of patients with PsA. ${ }^{16} 17$ This consistent observation emphasises the functional impact of large joint involvement in this patient population and suggests the need for a tailored and aggressive management of disease in large joints. Taking into account that the mean age of the patients who underwent these joint replacement surgeries was relatively young (51.35 $\pm 11.38 \mathrm{SD})$, we do not consider osteoarthritis as a main factor for the joint damage.

Unlike the previous studies in the literature, we also tried to see if different phenotypes of PsA behave differently and discovered that the patients with asymmetric oligoarticular arthritis had the most number of surgeries followed by symmetric polyarthritis and an unspecified form. ${ }^{17} 18$ This could also be an indicator that certain forms of PsA are more likely to undergo a surgical intervention as compared with the other forms and should be monitored closely for any radiographic changes or joint damage to reduce the risk of surgeries in these patients. There were a lot of surgeries performed before the patients were initially diagnosed with PsA and a large number of these include diagnostic arthroscopies and CTS. This is potentially an indicator of delay in diagnosis and treatment and can also be a reason for finding the high rate of surgical interventions and poor HAQ 3 score in our patients group. Haroon $e t a l^{22}$ showed that diagnostic delay of just 6 months leads to increased risk of joint erosions and poor long-term physical function outcomes and quality of life. This underlines the need for early diagnosis and referral to a rheumatologist and aggressive management of PsA from the very beginning to slow down the disease progression and improve the quality of life in these patients.

We did not find any statistically significant difference between the surgical and non-surgical groups based on their treatment. This could be due to some patient selection as the impact of mechanical factor on pain in a damaged joint may influence the decision-making process when starting biological therapy. Although anti-TNF $\alpha$ medications have shown to be more effective in controlling peripheral and axial disease, ${ }^{23}$ we still found higher prevalence of peripheral and axial disease in the surgical group as compared with the non-surgical group (table 3). The treatment paradigms in PsA are rapidly changing and our results represent the current treatment status of the patients. We do not have complete presurgical and postsurgical treatment data as almost $69 \%$ of the surgeries were performed before the patients were included in the SPAR cohort, and we lack details about prior treatment. So due to this limitation, we would not wish to comment further on the effect of therapy in the prevention of joint damage.

\section{CONCLUSION}

There are more number of surgical interventions in our PsA patient cohort as compared with historic figures 
reported in patients with PsA and RA even with a lower mean disease duration. There was a significant difference in HAQ scores between patients who underwent surgery or did not undergo surgery. Of interest, 36.07\% of the orthopaedic interventions were performed before diagnosis including $9.90 \%$ of diagnostic arthroscopies indicating a potential delay in diagnosis. The study results indicate that prevention of skeletal damage and the need for surgical interventions is important in patients with PsA. Early diagnosis and aggressive management of PsA from the very beginning to slow down the disease progression may reduce the risk of surgical interventions and provide an opportunity to improve the quality of life in these patients.

Acknowledgements The authors thank Abbvie, Belgium for their unrestricted financial support.

Funding The work was supported by the unrestricted Abbvie Chair for psoriatic arthritis research (RJL and KdV).

Competing interests None declared.

Patient consent Obtained.

Ethics approval Ethical approval was obtained from the Ethical Committee for Clinical Research at the University Hospitals Leuven.

Provenance and peer review Not commissioned; externally peer reviewed.

Data sharing statement The authors are willing to share the original data to the scientific community on request.

Open Access This is an Open Access article distributed in accordance with the Creative Commons Attribution Non Commercial (CC BY-NC 4.0) license, which permits others to distribute, remix, adapt, build upon this work noncommercially, and license their derivative works on different terms, provided the original work is properly cited and the use is non-commercial. See: http:// creativecommons.org/licenses/by-nc/4.0/

\section{REFERENCES}

1. Gladman DD, Antoni C, Mease $\mathrm{P}$, et al. Psoriatic arthritis: epidemiology, clinical features, course, and outcome. Ann Rheum Dis 2005;64(Suppl 2):14-7.

2. Moll JM, Wright V. Psoriatic arthritis. Semin Arthritis Rheum 1973;3:55-78.

3. Goldenstein-Schainberg C, Favarato MH, Ranza R. Current and relevant concepts in psoriatic arthritis. Rev Bras Reumatol 2012;52:98-106.

4. Day MS, Nam D, Goodman S, et al. Psoriatic arthritis. J Am Acad Orthop Surg 2012;20:28-37.
5. Rahman $\mathrm{P}$, Nguyen $\mathrm{E}$, Cheung $\mathrm{C}$, et al. Comparison of radiological severity in psoriatic arthritis and rheumatoid arthritis. J Rheumatol 2001;28:1041-4.

6. Ritchlin C. Psoriatic disease-from skin to bone. Nat Clin Pract Rheumatol 2007;3:698-706.

7. Finzel S, Englbrecht M, Engelke K, et al. A comparative study of periarticular bone lesions in rheumatoid arthritis and psoriatic arthritis. Ann Rheum Dis 2011;70:122-7.

8. van der Heijde D, Sharp J, Wassenberg S, et al. Psoriatic arthritis imaging: a review of scoring methods. Ann Rheum Dis 2005;64 (Suppl 2):ii61-4.

9. McGonagle D. Imaging the joint and enthesis: insights into pathogenesis of psoriatic arthritis. Ann Rheum Dis 2005;64(Suppl 2): ii58-60.

10. Torre Alonso JC, Rodriguez Perez A, Arribas Castrillo JM, et al. Psoriatic arthritis (PA): a clinical, immunological and radiological study of 180 patients. Br J Rheumatol 1991;30:245-50.

11. Kane D, Stafford L, Bresnihan B, et al. A prospective, clinical and radiological study of early psoriatic arthritis: an early synovitis clinic experience. Rheumatology (Oxford) 2003;42:1460-8.

12. de Vlam K, Lories RJ. Update in treatment options for psoriatic arthritis. Expert Rev Clin Immunol 2009;5:779-88.

13. van der Heijde D, Kavanaugh A, Gladman DD, et al. Infliximab inhibits progression of radiographic damage in patients with active psoriatic arthritis through one year of treatment: results from the induction and maintenance psoriatic arthritis clinical trial 2. Arthritis Rheum 2007;56:2698-707.

14. Mease PJ, Gladman DD, Ritchlin CT, et al. Adalimumab Effectiveness in Psoriatic Arthritis Trial Study Group. Adalimumab for the treatment of patients with moderately to severely active psoriatic arthritis: results of a double-blind, randomized, placebo-controlled trial. Arthritis Rheum 2005;52:3279-89.

15. Mease PJ. Psoriatic arthritis: update on pathophysiology, assessment and management. Ann Rheum Dis 2011;70(Suppl 1): i77-84.

16. Zangger $P$, Gladman DD, Bogoch ER. Musculoskeletal surgery in psoriatic arthritis. J Rheumatol 1998;25:725-9.

17. Zangger P, Esufali ZH, Gladman DD, et al. Type and outcome of reconstructive surgery for different patterns of psoriatic arthritis. J Rheumatol 2000:27:967-74.

18. Michet CJ, Mason TG, Mazlumzadeh M. Hip joint disease in psoriatic arthritis: risk factors and natural history. Ann Rheum Dis 2005;64:1068-70.

19. Belsky MR, Feldon P, Millender LH, et al. Hand involvement in psoriatic arthritis. J Hand Surg Am 1982;7:203-7.

20. Taylor W, Gladman D, Helliwell P, et al. Classification criteria for psoriatic arthritis: development of new criteria from a large international study. Arthritis Rheum 2006;54:2665-73.

21. Boonen A, Matricali GA, Verduyckt J, et al. Orthopaedic surgery in patients with rheumatoid arthritis: a shift towards more frequent and earlier non-joint-sacrificing surgery. Ann Rheum Dis 2006;65:694-5.

22. Haroon M, Gallagher P, Fitzgerald $\mathrm{O}$. Diagnostic delay of more than 6 months contributes to poor radiographic and functional outcome in psoriatic arthritis. Ann Rheum Dis 2015;74:1045-50.

23. Addimanda O, Possemato N, Caruso A, et al. The role of tumor necrosis factor- $\alpha$ blockers in psoriatic disease. Therapeutic options in psoriatic arthritis. J Rheumatol Suppl 2015;93:73-8. 